\title{
Operational and Strategic Decisions in Hospitality. Lessons from an Action Research Process
}

\author{
Amaya Erro-Garcés \\ https://orcid.org/0000-0002-1858-1363 \\ Universidad Pública de Navarra, Campus Arrosadia s/n, 31006, Pamplona, Navarra, Spain \\ Laura Ramírez-Ávila \\ Universidad Pública de Navarra, Campus Arrosadia s/n, 31006, Pamplona, Navarra, Spain
}

\begin{abstract}
The aim of this article is to find measures that reduce personnel costs in a catering company through the optimization of routes and tasks for staff to increase the efficiency of the company, and to transfer these measures to the sector as a whole. This paper is based on action research methodology which facilitates both taking action and creating knowledge or theory about the action analysed. Findings demonstrate that the solution focused on minimization of the workers' operations and optimization of routes does not solve the problems identified in the company. The flexibility of action research allows adaptation of the focus on the needs of the company, and both the problem and solution are redefined. Thus, a discovered relationship between operational and organizational management is the main outcome obtained in the research. As a result, six proposals are described: clarifying task assignments, improving organizational management and the estimation of provisions, optimizing routes, reducing personal services, and improving human resources policy. It is concluded that the performance of both manager and employees is influenced by the organizational strategy.
\end{abstract}

Keywords: action research; productivity; optimization; catering company; operations

Corresponding author: Amaya Erro-Garcés, Public University of Navarre, Campus Arrosadía s/n, 31006 Pamplona, Navarra (Spain); amaya.erro@ unavarra.es; Tel. 0034948196081 


\section{Introduction}

According to Eurostat, the service sector is the most dominant sector in the economy. It is defined as the "current and future motor for growth in Europe" (Eurostat 2019). In this context, the tertiary sector represents almost 75 per cent of Spanish production and is responsible for two thirds of all jobs in the country.

The service sector groups many subsectors with different activities. One of them, which is the focus of this article, is the hotel sector and, more concretely, the catering sector. As stated by the Spanish Association of Franchisors (2018), the hotel sector has a great impact on the country's economy. In 2017, it contributed to 8 per cent of the national GDP. With regard to employment, the hotel sector generates around 1.6 million job vacancies each year (Aragonés, 2017). Therefore, it can be seen as one of the most important Spanish activities. On the other hand, it should be considered as a complex sector and, consequently, its organization and management are not simple.

Most of the problems handled by this sector are related to human resources management. The main difficulty is dealing with growing demand. As Garrido (2017) stated, "according to the EPA data (Active Population Survey), the service sector contributes to $75.6 \%$ of Spanish employment while before the crisis it was 9 points fewer". The increasing importance of the hotel sector and its growing demand lead to two main impressions. Firstly, employment is growing too; and secondly, it implies high expenditure. Therefore, even a company with high income assumes high personnel expenses that can lead to poor profitability.

This situation justifies the present article, which is based on experimental research in a company in the hospitality sector, Serunion, and particularly, Singularis, its catering service brand. An action research methodology is used to analyse the company and look for solutions that could be applied not just in this company, but in the sector as a whole.

In order to reduce personnel costs, the research objectives are to optimize routes and tasks for staff to increase the efficiency of the company, and to transfer the proposed measures to the sector as a whole. The main intention of this article is to find a way to reduce workers' work-time and therefore reduce costs and increase profitability. For this purpose, the research is based on observation of waiters' operation and its optimization.

The article has the following structure. Firstly, the theoretical background is presented, and then the methodology used for the research is described. Next, the process of the research is developed, starting with the planning and finishing with the analysis of the results. Finally, the article offers a series of conclusions and recommendations.

\section{Theory}

\section{Optimization of routes}


The optimization of routes and tasks solves problems in the cheapest and most efficient way. This technique has the potential to generate savings on logistical costs by defining more intelligent routes where workers spend less time at work, and the company therefore reduces its costs, in particular, personnel expenditure. At the same time, greater task efficiency supposes fewer workers involved in the same tasks, which can reduce costs further. On the other hand, as Olate (2016) affirms, new routes could imply greater satisfaction for clients derived from a better delivery rate. As a result, the company's income also increases as it attracts new customers or increases the loyalty of existing clients. However, given that there are many factors to take into account, designing optimized routes and tasks is not easy.

Several authors have studied operational optimization in the service sector. Akkerman et al. (2010) worked on the food distribution sector and the problems of quality and sustainability. Geoffrion (1974) described a model to determine the location of intermediate facilities between plants and customers for a food firm. Gelders et al. (1987) performed an analysis in the beer industry, while Wu et al. (2017) developed a distribution system for high-speed railways.

More specifically, in the catering sector, Wright and Pollert (2005) identified both positive experiences and problems encountered by ethnic minority and immigrant workers in catering routes. In a similar vein, Jansen et al. (2001) developed a simulation model in the catering supply chain.

Nevertheless, no previous research have been found to analyse catering industry operations though an action research methodology. Therefore, this study aims to fill this gap by conducting an action research study in a catering company.

\section{Action research}

Action research (hereafter, AR) is an approach to research that aims both to take action and to create knowledge or theory about the action (Coghlan 2002; Coughlan and Coghlan 2002). The term was first used by Lewin in 1946. According to Rapoport (1970, 499), "action research aims to contribute to the practical concerns of people in an immediate problematic situation and to the goals of social science by joint collaboration within a mutually acceptable ethical framework".

AR facilitates joint investigation and consulting activities and brings together researchers and companies in the case of business research. In other words, AR tries to understand the problems (research) and solve them through practice (action) — that is, it has a practical nature. Both the research and the action are part of the process (Alfaro and Avella 2013). The participation of the organization in the study will increase both the authenticity and the trustworthiness of the results, considering that the analysis is conducted in a collaborative manner (Argyris and Schön 1991). Thus, the researchers obtain more rigorous information and the study is more valuable for the entity that contracts it. However, Baskerville and Wood-Harper (1996) and Gummesson (2000) warn that consultants typically operate under tighter time and budget constraints, which may limit the ability to reflect on both the research process and the results.

On the other hand, Coughlan and Brannick (2001) contend that sometimes there are better techniques than AR to solve this type of problem. In fact, AR is adequate when the research question relates to describing an unfolding series of actions over time in a given organization, and the problem is therefore understood and a possible solution can be found (Coughlan and Coghlan 2002). The company's co- 
operation is needed in order to get all possible information and data about the problem and so arrive at a better understanding.

\section{Action research and hospitality}

Although extant publications on AR have focused on operations (e.g. Coughlan and Coghlan 2002; Karlsson and Åhlström 1996;Westbrook 1995) or education (e.g. Clift et al. 1990; Cochran-Smith et al. 1988; Gore and Zeichner 1991; Ross and Anand, 1987), this methodology has been used in the hospitality sector.

Regarding the implementation of AR in the hospitality sector, many articles focus on the hotel sector. For example, Waser and Johns (2003) worked on cross-cultural communications in hotels, Chan et al. (2013) evaluated the application of solar energy for hot water provision, and Chan et al. (2015) developed an experiment to improve air quality in hotels.

Nevertheless, the application of AR in the food industry is not new. Kocher et al. (2011) analysed the capability to innovate in a company that operated in the food industry, while Wouters (2009) developed an AR project to study a restaurant chain.

Finally, as mentioned, no previous research using the AR methodology has been found in the catering sector. This article aims to fill this gap by conducting an analysis of operational management. Once the problem has been deeply studied, the focus of the research will move from operations to strategic theory, as will be described.

\section{Action research phases}

Action research is developed in several phases, in a similar structure to other case research (e.g. Dubé and Paré 2003; Marshall and Rossman 2006; Miles et al. 1994; Stuart et al. 2002; Voss et al. 2002; Yin 2003).

As Butler et al. (2008) assert, the approach takes place in two stages. The first stage involves diagnosing the problem to be solved, the second collaborative application of the theory to guide actions to address the identified problems. However, Coughlan and Coghlan (2002) and Westbrook (1995) summarized an AR performance model that is explained in five stages: recognition and diagnosis of the problem, action planning, action taking, assessment of results, and report generation.

Figure 1 presents the phases of the methodology that should be repeated until the problem is solved. In most cases, the first cycle is not enough to solve the problem.

\section{INSERT FIGURE 1 HERE}

The AR methodology is not a fixed process; in fact, each action research has its own diverse process, as presented in Figure 2.

INSERT FIGURE 2 HERE 
It is important to highlight that $\mathrm{AR}$ is a theoretical-practical research that requires security and experience that it is not always accurate, so that the results are sometimes not as expected.

\section{Materials and methods}

\section{Data}

Firstly, it is important to contextualize the research. As mentioned, the research focuses on a catering company called Singularis. This is one of the 13,780 catering companies that constitute the Spanish catering industry, an industry that is growing continuously.

Despite the deceleration in growth, demand for catering companies is increasing. As a consequence, the problems of facing such growing demand will not disappear. Those problems have made Singularis inefficient, and lead to a larger problem: the public call for tenders for Baluarte's catering. That call was resolved last August in favour of another company, Vicastelar Services S.L. This company will start its business in Baluarte in 2019. This decision implies that Singularis will not work in Baluarte's catering services.

\section{Diagnosis and problem definition}

Serunion, the business group to which Singularis belongs, is a company created 30 years ago. It offers catering services in different places around the country. In this case, the study is focused on the catering offered in Baluarte, a building for cultural events in Pamplona, Navarra.

Among the objectives of the company, the wish to serve quality dishes meeting nutritional requirements to offer a quality and healthy diet can be highlighted. As the official website shows, the company has around 2,920 food centres. Therefore, it can be expected that the pre-service work is complex to manage and the company spends a long time organizing different diets, dishes and menus depending on the place, time and clients. Serunion has around 470,000 diners daily around all the national centres, with an annual turnover of 445 million euros or more.

However, the company has a problem deriving from the huge cost of hiring staff. Serunion has more than 19,000 employees with which to face the growing demand. Because of the growing costs, there is a wish to optimize the cost of personal in the catering services in Baluarte. This optimization aims for a service with the greatest viability and quality, at all times meeting the clients' requirements.

To perform the optimization, and according to the information facilitated by the company, workers are paid according to the hours worked. Therefore, the fewer hours worked, the lower the salary and the higher the saving for the company. It is important to keep in mind workers' profiles. This is a case study where the workers are occasional: they are hired exclusively to offer services for different events during specific hours. The structure of the workforce is sixty per cent student and thirty per cent people that were unemployed; the rest are people working in the sector. Accordingly, this type of worker is not the most effective, particularly in the Baluarte building, which is very complex and it is easy to get lost: in fact, if workers were permanent, there would be fewer problems. 
Because of the complexity of the building and the profile of the workers, the waiters take too much time preparing the rooms in which the events are held. Moreover, the preparation and service of the dishes also take a long time. The solution to these problems is the optimization of routes, together with some different techniques to optimize the time spent on different tasks.

Through this mechanism, there will be new and more efficient assignments that save workers' time. These problems were described by the company, and managers from the company took an active role in defining the main research questions jointly with the researchers. It is important to emphasize that an interactive relationship between the researchers and the workers - in this case, waiters - is essential in AR. If they do not collaborate, it is be almost impossible to develop an AR project.

\section{Action research planning}

The first decision is related to the value of developing the research. The expected improvement for the company if the problem is solved should be considered. In this sense, the personnel costs for the company are analysed, as they are the highest expenditure. Seeking a reduction in these costs will suppose a significant improvement for the company and, as a result, the research is of value. The company's decision about the research was relevant to decide the focus of the study. Managers showed the importance of the research to understand the main variables that determine the company's productivity. As a result, the research was approved and the company decided to participate actively in the process.

Another factor to include in the analysis is related to the cost of the research. In this case, the research incurs no costs. If there were costs, the company should evaluate the profitability of developing the research or not and compare the results.

After deciding to carry out the research, the researchers should ask themselves how the problem might be solved. The problem of the catering company case could be answered, in principle, by optimizing the operation of the waiters. As mentioned, the problem was jointly described with the organization. Managers pointed about importance of the costs and optimization of the operational process. Nevertheless, according to AR methodology, this plan is not unchangeable; in fact, it will vary as the research goes on.

In this step, it is important to make sure that the chosen methodology is the right one. The previous section tested this with a deep explanation of AR, concluding that the action research process is the best way to resolve the issue.

Finally, a critical analysis of the expected results is required. In the studied case, an improvement in workers' productivity is expected, reducing personnel costs and increasing the company's benefits. This should be calculated numerically and the company should participate in its analysis.

\section{Data collection}

Data were collected mainly through an observation technique, although some information was given by the event organizer. 
- Place where the action research will be carried out: Baluarte (Pamplona, Navarra)—specifically, the rooms or spaces where the catering services are developed.

- Members who are going to be studied: Waiters in charge of serving at the different events. This information is not always the same. The workers are hired casually; therefore for each of the events around which the research is based, the workers were different. It might be more accurate if the research involved the same workers.

- Participatory research: The organization was involved in the research process in several ways. Managers from the company helped the researchers to define the events that represent the whole activity of the company. Data justifying the selection of the event were shown by the company.

- Data collection

i. Data collection method: Data collection was through an app on workers' mobile phones which counts the steps of each worker. The name of the app is Podómetro. The Podómetro app is a free download that records the number of steps taken and shows the caloric consumption distance, walking time and speed. It measures the effort of each of the workers and the distance of their routes. Each waiter downloaded it on their mobile. They pressed the start button just before starting to work, and at the end of the work time they recorded the number of steps taken. The app therefore started working when the workers began preparing the room and it stopped working when they finished clearing everything. The organizer had to ask permission for the waiters to carry the mobile with them; they are not otherwise allowed to use mobiles during an event.

ii. Date of the collection: From March to July, the planning of four different events was analysed. Data were collected from the events from September to November.

iii. Data analysis: The analysis is finally described in the next section.

Data analysis

To collect data, the operation process in different events is observed , as the company offers a wide range of different catering services but there is a process that every event follows.

The first issue considered is the event size, depending on which the company decides on the number of workers to hire. The staff used include cooks, waiters, a head waiter and an organizer. In contrast to the waiters, the roles of head waiter and organizer are always given to the same person.

The working day of the staff begins before the event. The cooks work hard from very early in order to get the food ready for an event; the waiters also start working some hours before since, apart from serving the food, they also have to prepare the event room and a space, called the office, next to the event room. This research is focused on the waiters' work.

As mentioned, the workers are in charge of preparing the event space. This action takes between an hour and an hour and a half, depending on the event size. However, because of the complexity of the building, the time to prepare will also vary depending on the floor where the event is located. The main issue is that the things needed to prepare the room are on different floors of the building. For example, the kitchen is 
in the basement -1 , while the tables and the tableware are on the second and third floors respectively. Moreover, the routes involve the use of just two lifts. Therefore, the routes to prepare and collect are complex and difficult to optimize.

On the other hand, the waiters also have to prepare an office next to the event room. The aim of this small space is to have everything at hand to serve. It is next to the main room to allow the simplest and shortest route to serve the food. Therefore, optimization of routes and actions is focused on the preparation and the clearing.

Preparation of the event room consists of assembling the necessary tables and dressing them. There is also a bar, used for the purchase of special drinks. The office room is where the cooks plate the dishes and where the waiters collect and return their trays.

The distribution of the waiters around the room is decided by the head waiter. Just a few minutes before starting the event, there is a meeting in which the head waiter assigns each worker their task during the event. Basically, the distribution consists of putting someone in charge of drinks and others in charge of the food. Moreover, there is always one waiter, at least, in charge of the bar.

After the event, the waiters have to clear the room and the office. They have to collect all the glasses, plates and cutlery in order to wash them. They also have to collect the tableware for washing, and collect and store the drinks and glasses not used during the event.

Although the research is based on more events, two particular events will be considered to demonstrate the problem in the company.

12th September. Cocktails were served for guests at a Law School lecture. The even took place on the ground floor and the number of guests was around 300. In this case, the company decide to hire 11 waiters and waitresses to manage 12 tables. The average number of guests per worker was approximately 30. In addition to these workers, the head waiter and the organizer were at the event.

The event started at 13:15 and all the waiters worked from 11.30. In this event, they had to collect the furniture to assemble in the hall from floor-1 and the second floor. The event lasted until 15.00, at which time the waiters had to clear everything. A few minutes before 13:15, the worker head told them that one of the waiters was going to be located in the bar, half of them were in charge of drinks, and the other half were in charge of the food.

Although the workers' route to serve the food was quite simple, complex routes were used to prepare the rooms. To prepare this event required equipment from the basement -1 , where the kitchen is located, and from the second floor warehouse.

14th September. This event was smaller; the guests numbered around 150 people. The cocktails were prepared for a lecture about the integration of occupational health and public health. The company hired five waiters, so the average was 25 customers per worker. Their working day started at 12:30 and the 
cocktail party started at 13:45. The cocktail party took place on the third floor, which made preparation easier: the tables were on the same floor, and they also just needed some tableware from the basement -1 .

There were six tables and a bar, so, there were four waiters around the room and a waiter behind the bar. The waiters serving the cocktails were distributed according to their tasks: three were in charge of serving the food and one was in charge of collecting the rubbish and the empty glasses from the tables.

The event lasted until 14:40, but the waiters did not clear the room. The next day, 15th September, there was a wedding in the same room, so they took advantage of this and, instead of clearing it, they put in more tables and chairs to prepare the room for the wedding.

This event was simpler than the previous one. The workers took the equipment from the same floor as the event, so the only route was from the kitchen to the event floor.

Every event needed to carry the food from the kitchen to the event floor. Depending on the floor on which the event was being held, the route varied, but there was always a need to use the lift to move between floors.

On the other hand, the tableware was stored on the second and third floors.

The Podómetro app also counted the steps taken by the waiters. Table 1 shows the number of steps taken.

\section{INSERT TABLE 1 HERE}

The table differentiates the events in order to compare the productivity of both events. Figure 3 contributes to the analysis and comparison of the events.

\section{INSERT FIGURE 3 HERE}

Observing the data, several conclusions can be drawn. The data show some differences among workers. These differences can be interpreted in different ways, one of which is related to productivity.

From the data collected from the app, it can be observed that there is a waiter who takes fewer steps, specifically waiter number 5. It is assumed that this worker is the one working in the bar (Table 1). That worker is not busy most of the time, so will take fewer steps than the others.

Nevertheless, there are still differences among the rest of waiters. These variations are considered as the differences in productivity and differences in the length of the routes taken. There are two ways to interpret them. On one hand, it is expected that the workers who take more steps are more productive, since they work more; but, on the other hand, it is also possible that the workers who take more steps are less efficient.

Regarding the latter thought, in general terms, when the worker has only recently been hired, he is likely to get lost in the building: it takes a while to learn the routes and to get used to the pace of work. In addition, workers will sometimes, in order to work less and put in less effort, pretend that they got lost. 
However, there are also reasons in favour of the notion that waiters taking more steps are more therefore complete a task more quickly, thus taking on more tasks than another waiter and, as a consequence, taking more steps. This fits the role of the more experienced waiters.

During observation of the events, it was concluded that this case supports the idea that the workers who take more steps are the most productive workers. That does not mean that this will be true in all caseseach case has its own interpretation - but it is the case here. Here, the worker who took most steps (waiter number 1 , Table1 is also the most experienced worker.

Another important point to take into account to analyse the data from the app is that waiters knew that someone was watching and evaluating them. As a consequence, some of them were probably working more productively than if nobody was watching. This can be generalized to any worker, as every worker tries harder when they know they are being watched. It is also true that this method does not automatically improve productivity, since it can sometimes encourage workers to pretend that they are working.

There are further differences between the two events. Because the events took place on different floors, it was not possible for the workers to take the same number steps in the different spaces. For example, events which are held on the ground floor, as it is a bigger space, will cause workers to take more steps than events on the third floor. The distance between the office and the event room also affects this situation.

\section{Action planning}

After analysing the data, some conclusions can be arrived at. Firstly, a better definition of the problem can be achieved. The problem being faced is lack of productivity as a whole. It is true that there are problems with workers' productivity, but also there is the need to improve organizational strategies.

Because of the complex distribution around the building of the equipment necessary to prepare the event room, waiters spend a lot of time moving things upstairs and downstairs when preparing and clearing up. As the distribution of the things cannot change, this research seeks to find the best routes to minimize the working time.

Taking into account all the information observed, action planning is based on six proposals.

\section{Proposal 1. Clarify task assignments}

The first proposal to minimize working time is to improve the planning of tasks. The research shows that the working day starts with all the waiters setting out the event room and the office. When the event is large, the company hires many waiters and there are therefore too more waiters than are needed to set out the room. Taking into account that there are only two lifts, the routes will be more efficient with fewer waiters setting out the spaces. The recommendation is to reduce the number of waiters setting out the room. 
Moreover, the distribution of tasks must be clarified - that is, each worker should know what his aim is at every moment. The objective is to reduce the working time of every worker, so if they distribute more simple tasks, the productivity of the waiters will improve.

Indeed, the idea of each waiter knowing his or her task just a few minutes before the event may not be the best. It would be helpful for the waiters to know their tasks as soon as they start working. Even more, they should not change their assigned tasks for different events: that would be helpful for a waiter repeating the task at the next event, and would lead to specialization.

\section{Proposal 2. Improve organization}

This proposal is related to the distribution of the office. As was explained, the office is the place where everything is prepared to serve the food.

The organization of the office is not the best. There are usually tables where the cooks have to plate the food, and the waiters have to serve the beer, prepare their trays, and leave the rubbish, plates and glasses collected from the event room. All these actions are done using the same tables without any organization. The only differentiation is between the cooks' and the waiters' place. If there is better organization of the tables, workers will be faster and they will spend less time.

\section{Proposal 3. Improve estimations}

The next proposal focuses on the differences between estimation and the real situation. The waiters have traditionally prepared drinks and food for the events - that is, estimated the drinks, food and services that will be used for an event. However, that estimation usually does not fit with the real situation.

It is evident that it is better to have too much than too little; but the problem is that everything prepared to serve that is not served must be collected again, and it requires more time spent working. If the estimations are more adjusted to the reality, the waiters will save working time.

Moreover, better estimation will increase the benefits for the company. If waiters prepare just the quantity to serve, there will be less waste and there will be better use of the food and drinks by the company.

\section{Proposal 4. Optimize the routes}

The optimization of routes is one of the principal objectives of the research, so a plan is needed to implement better routes. The routes can be optimized in several ways. One of them is mentioned in the proposal 1: the waiters should be assigned different tasks to help create more efficient routes to set up the spaces.

On the other hand, routes could be made more efficient by using a trolley to move things in a faster and more comfortable way. The waiters dress the tables bringing equipment on trays: they would take less time using a trolley, since they can bring more things in a single trip and with less risk of dropping it.

Proposal 5. Reduce personal service 
The food is served by the waiters. They take their trays with drinks and food from the office and they go This proposal seeks to leave some foods and drinks on the tables. In the case of drinks, they already do, except with the beer. But, in the case of food, the company will need fewer waiters if they leave some of the snacks on the table.

Hiring fewer waiters means a reduction in personnel costs, and this leads to an increase in the company's benefits. This completes another of the company's objectives.

\section{Proposal 6. Modify the human resources policy}

The human resource policy followed by Serunion is based on casual work contracts. As mentioned at the beginning of the article, a high proportion of the waiters are students with no experience, and the rest of the worker are foreigners who are working on this job because they cannot find another one.

The proposal is to change the way to hire waiters. The company should look for loyal and experienced waiters. This would increase the productivity of the company in many ways. For example, the workers will not need a lot of preparation time. Another point is that if the workers work for the company for a long time, the complexity of the building will not be a problem.

Once we have the proposals for action, the next step is to implement them.

\section{Implementation of the actions}

This step of the research differs a little from the general process. This is because Serunion lost its place in Baluarte last August through a call for tenders, and so the company will not be able to implement the actions. In the place of Serunion is a new company, Vicastelar Servicios S.L.

At NICDO (Navarra Infraestructuras de Cultura, Deporte y Ocio), the process to choose the new company was based on economics, sustainability, brand and image, and logistics and services.

Taking into account these components, Vicastelar Servicios S.L. made the best offer. They were valued because of their use of seasonal and local raw materials and because of the development of a corporate social responsibility programme. Moreover, they stated that "The Company makes a social commitment that favours labour insertion - including people with disabilities or functional diversity — and promotes equal opportunities, and also guarantees the subrogation of the staff currently employed." This supports the proposal of changing the human resources policy.

According to its business in Baluarte, Vicastelar Servicios S.L. is in charge of the coffeeshop, and three restaurants inside the building, one on each floor. The restaurant located in the ground floor is a finger food restaurant - that is, a restaurant serving food that can conveniently be eaten with the fingers. However, the restaurants on the second and third floors offer a gourmet menu specializing in vegetables. 
Apart from these services, the company also offers the catering service on which we have focused the research. Concretely, the services will be for events, weddings and banquets. The company also organizes the coffee shop service and fixed and mobile bars.

Despite the fact that Serunion will not implement the actions recommended in Baluarte, the research could help both Serunion and the mentioned new company. Regarding Serunion, implementation of these proposals could improve many of the other businesses of the company. The research can be useful in relation to similar problems in other places, because the way the company operates in Baluarte is perhaps similar to the way it operates elsewhere, and it might have problems with organization of which it is not aware.

New data collection was performed in June 2019, after modifying the human resources policy (new waiters had previous experience and they had higher training), clarifying the previous tasks of each employee, decreasing the quantity of drinks and food, and reducing the number of waiters. Two cocktail parties pertaining to a meeting in Plant Science and GICCA 2019, an Ibero-American Conference, were selected to measure the operational process. Table 2 shows the outcomes of the new measurements.

\section{INSERT TABLE 2 HERE}

Just four waiters worked at each event. All employees reduced their step count for the first event, except for waiter number 2 .

If we compare total steps from the first measurement and the second, in 2018, 47,979 steps were counted, whereas in 201938,705 were taken to perform the same service, which is a reduction of 19.32 per cent.

More experienced and trained employees imply higher wages. However, as the new catering company has reduced the number of employees, total expenditure has been reduced. As a result, workers' productivity has improved.

Despite the research being focused on a specific company and a specific situation, its conclusions are also appropiate to most service sector companies. The organization management of the business is as important as the operations management. That is, the operation of a company depends on the workers' productivity, but it also depends on the department that coordinates and organizes their tasks. Therefore, most of the proposals can be generalized to different companies.

For example, the first proposal is applicable to any company. Every worker will work in a more efficient way when the tasks assigned are clear. Here, neither the building nor the company matters: the productivity of a worker will increase when the tasks are clear, independent of the context.

The same reasoning can be applied to the sixth proposal. The human resources policy significantly affects workers' productivity. When a worker is loyal and permanent in a company, he or she would be more satisfied and, as a consequence, the worker will be more productive. 
Other proposals can be applied to some companies of the sector, like the third proposal. The estimation of materials is essential for any company in any catering sector. If these materials do not fit the needs, there can be huge losses for the company.

It can therefore be concluded that the proposals made can be implemented in many other companies in addition to Serunion and Vicastelar Services S.L. The implementation leads to a new analysis, which is of the consequences or results.

\section{Results and discussion}

This section analyses the consequences of the implementation of the actions. Table 3 shows the consequences expected of each of the proposals identified to improve and solve the problem.

\section{INSERT TABLE 3 HERE}

The proposal of assigning the waiters to clearer and simpler tasks leads to faster work, since they are focused on their tasks instead of looking for something to do. Furthermore, if they repeat the same task over time, they will reduce the time needed to perform the task.

The second change gives rise to a more organized way to work, in that the waiters spend less time in the office searching for a place to put dirty cups and plates on the table. At the end of the event, they also spend less time clearing the office.

Regarding the third proposal, the waiters spend less time both preparing and clearing overestimated food, drinks and glasses. It also saves the company money, since it uses almost all the estimated quantities without creating a surplus.

The fourth and fifth proposals refer to the main objective of the research - that is, to optimize the routes of the waiters. This saves money through the need to hire fewer workers while, at the same time, they complete the same tasks faster and more effectively.

Finally, the change of human resources policy implies a huge improvement for the company.

Apart from the expected results, it is important to highlight some further implications of the research. Regardless of the implementation of the action, the research shows the strong relationship between operations and organization management. This suggests that proper allocation of the organization's resources, such as the workers, is essential to achieve the objectives of the company.

Brown et al. (2013) argue that most CEOs and other senior-level managers struggle to articulate a strategy, but they fail to share and implement the strategy with all employees. This is made worse because many CEOs know very little about operations management.

In this vein, Mathis and Jackson (2007) show the importance of having the right human resource management for the company's strategies. Figure 4 presents the relationship between the organizational strategy and its results. 


\section{INSERT FIGURE 4 HERE}

As Figure 4 shows, the performance of the management of both practices and employees is influenced by the organizational strategy. At the same time, the outcomes of the company depend on that performance.

As a conclusion, the solution to the performance of workers is related to revision and improvement of the organizational strategy. Once the optimal organizational strategy is found, the results of the company will improve in terms of both productivity and profitability.

\section{Conclusions}

Action research is proposed as the best way to find the solution to the problems identified in a catering company that aims to reduce personnel costs. As AR is individualized and flexible, it allowed researchers to recognize more problems than the ones initially identified. The research focused firstly on the optimization of routes. Nevertheless, more problems were found related to organization management difficulties.

As a result of the complexity of the building, the routes of the waiter cannot change; they are already taking the simplest way. However, the company can improve its productivity by adapting and altering several operational aspects. As a result, six proposals are identified: clarifying task assignment, improving organizational management and the estimation of provisions, optimizing routes, reducing personal services and improving the human resources policy. The first proposal is the need to clarify the tasks assigned in order to perform more productively. The second proposal is related to making better estimations of the provisions required for each event. Through this technique, both profitability and productivity improve. At the same time, the fourth and fifth proposals lead to the same tasks being performed in less time and by fewer workers. Optimizing the routes and reducing the personal service improve both productivity and profitability. Finally, changing the human resources policy helps to form a loyal and permanent workforce. It improves the workers' satisfaction and therefore their productivity.

The implementation of these proposals is essential for the research and, in this case, a new company conducted the implementation. They performed the same service in the same location. Furthermore, this new company has a different human resources policy which allows us to study the implementation of the sixth proposal. Indeed, the proposals can be implemented not just in the new company, Vicastelar Services S.L, but also in many other companies in the sector.

Overall, the research has highlighted a significant relationship between operations management problems and organizational strategies. As has been explained, having the right people in the right place at the right time is critical to make the overall strategies work. Therefore, if the workers' organization strategy is not synchronized with the operational strategies, problems appear. In order to avoid problems, the optimal solution is to work on the organizational strategies. 
Like every research, this study presents some limitations. Firstly, there were difficulties measuring the implementation of the proposals defined, as a new company is in charge of the hospitality service. Secondly, the conclusions depend on the situation of the catering company analysed. Nevertheless, human resources problems are found in most companies in the sector. For that reason, the conclusions are also relevant for other companies.

Further research should include measurement of the identified proposals in other companies in the sector. Developing new analyses in different countries and cultures will facilitate extending the results to other contexts.

\section{Funding}

This work was supported by the Ministerio de Economía, Industria y Competitividad and Fondo Europeo de Desarrollo Regional (FEDER) under Grant ECO2017-86305-C4-4-R. 


\title{
References
}

\begin{abstract}
Akkerman R, Farahani P, Grunow M (2010) Quality, safety and sustainability in food distribution: a review of quantitative operations management approaches and challenges. OR Spectrum 32(4):863-904. https://doi.org/10.1007/s00291-010-0223-2
\end{abstract}

Alfaro JM, Avella L (2013) Investigación en acción: cómo impulsar la contribución de la universidad en la competitividad de las organizaciones. Harvard Deusto Business Research 2(2):89-101. https://doi.org/10.3926/hdbr.33

Aragonés J (2017) La hostelería supone un 8\% del PIB nacional. Efe Empresas. Madrid. 11 August 2017. https://www.efeempresas.com/noticia/hosteleria-8-pib-nacional/ Accessed on January 2019.

Argyris C, Schön D (1991) Participatory action research and action science compared. In: Whyte WF (ed) Participatory action research. Sage Focus Editions, London. http://dx.doi.org/10.4135/9781412985383

Baskerville R, Wood-Harper T (1996) A critical perspective on action research as a method for information systems research. Journal of Information Technology 11(3):235-246. https://doi.org/10.1080/026839696345289

Brown S, Bessant J, Lamming R (2013) Strategic operations management. Routledge, London.

Butler T, Feller J, Pope A, Emerson B, Murphy C (2008) Designing a core IT artefact for knowledge management systems using participatory action research in a government and a non-government organisation. The Journal of Strategic Information Systems 17(4):249-267. http://dx.doi.org/10.1016/j.jsis.2007.10.002

Chan W, Lee SC, Hon A, Liu L, Li D, Zhu N (2015) Management learning from air purifier tests in hotels: experiment and action research. International Journal of Hospitality Management 44:70-76. https://doi.org/10.1016/j.ijhm.2014.10.007

Chan WW, Li D, Mak B, Liu L (2013) Evaluating the application of solar energy for hot water provision: an action research of independent hotel. International Journal of Hospitality Management 33:76-84. https://doi.org/10.1016/j.ijhm.2013.01.008

Clift R, Veal ML, Johnson M, Holland P (1990) Restructuring teacher education through collaborative action research. Journal of Teacher Education 41(2):52-62. https://doi.org/10.1177/002248719004100207

Cochran-Smith M, Kahn J, Paris CL (1988) When word processors come into the classroom. Writing with computers in the early grades, 43-74.

Coghlan D (2002) Interlevel dynamics in systemic action research. Systemic Practice and Action Research 15(4):273-283.

Coughlan P, Brannick T (2001) Doing action research in your own organization. Sage Publications, London. 
Coughlan P, Coghlan D (2002) Action research for operations management. International Journal of Operations \& Production Management 22(2):220-240. https://doi.org/10.1108/01443570210417515

Dubé L, Paré G (2003) Rigor in information systems positivist case research: current practices, trends, and recommendations. MIS Quarterly 597-636.

Eurostat (2019) Annual national accounts. https://ec.europa.eu/eurostat/data/database

Garrido HM (2017) España revive por los servicios, el único sector que recupera el empleo y PIB perdido en la crisis. 20 minutos. Madrid. 15 May 2017. https://www.20minutos.es/noticia/3033212/0/espanasector-servicios-base-recuperacion/ Accessed on January 2019.

Gelders LF, Pintelon LM, Van Wassenhove LN (1987) A location-allocation problem in a large Belgian brewery. European Journal of Operational Research 28(2):196-206.

Geoffrion AM (1974) Lagrangian relaxation for integer programming. In: Approaches to integer programming. Springer, Berlin, pp 82-114.

Gore JM, Zeichner KM (1991) Action research and reflective teaching in preservice teacher education: a case study from the United States. Teaching and Teacher Education 7(2):119-136.

Gummesson E (2000) Qualitative methods in management research. Sage, London.

Jansen DR, Van Weert A, Beulens AJ, Huirne RB (2001) Simulation model of multi-compartment distribution in the catering supply chain. European Journal of Operational Research 133(1):210-224.

Karlsson C, Åhlström P (1996) Assessing changes towards lean production. International Journal of Operations \& Production Management 16(2):24-41.

Kocher PY, Kaudela-Baum S, Wolf P (2011) Enhancing organisational innovation capability through systemic action research: a case of a Swiss SME in the food industry. Systemic Practice and Action Research 24(1):17-44.

Lewin K (1946) Action research and minority problems. Journal of Social Issues 2(4):34.

Marshall C, Rossman G (2006) The how of the study: building the research design. In: Designing qualitative research, 55-101.

Mathis RL, Jackson JH (2007) Human resource management. South-Western College Pub, Cincinnati.

Miles MB, Huberman AM, Huberman MA, Huberman M (1994) Qualitative data analysis: an expanded sourcebook. Sage, London.

Rapoport RN (1970) Three dilemmas in action research: with special reference to the Tavistock experience. Human Relations 23(6):499-513. 
Ross SM, Anand PG (1987) A computer-based strategy for personalizing verbal problems in teaching mathematics. ECTJ 35(3):151-162.

Spanish Association of Franchisors (2018) Franchising in Spain report 2018. http://www.franquiciadores. com/wp-content/uploads/2018/04/Franchising-in-Spain-AEF-National-Statistics-2018.pdf Accesed on January, 2019.

Stuart I, McCutcheon D, Handfield R, McLachlin R, Samson D (2002) Effective case research in operations management: a process perspective. Journal of Operations Management 20(5):419-433.

Voss CT, Tsikriktsis N, Frohlich M (2002) Case research in operations management. 22(2):195-219.

Waser H, Johns N (2003) An evaluation of action research as a vehicle for individual and organisational development in the hotel industry. International Journal of Hospitality Management 22(4):373-393.

Westbrook R (1995) Action research: a new paradigm for research in production and operations management. International Journal of Operations \& Production Management 15(12):6-20.

Wouters M (2009) A developmental approach to performance measures-Results from a longitudinal case study. European Management Journal 27(1):64-78.

Wright T, Pollert A (2005) The experience of ethnic minority workers in the hotel and catering industry: routes to support and advice on workplace problems. Working paper.

Wu X, Nie L, Xu M (2017) Designing an integrated distribution system for catering services for highspeed railways: a three-echelon location routing model with tight time windows and time deadlines. Transportation Research Part C: Emerging Technologies 74:212-244.

Yin RK (2003) Case study research: design and methods. Sage, Thousand Oaks, CA, London. 
Figure 1. Action Research Cycle

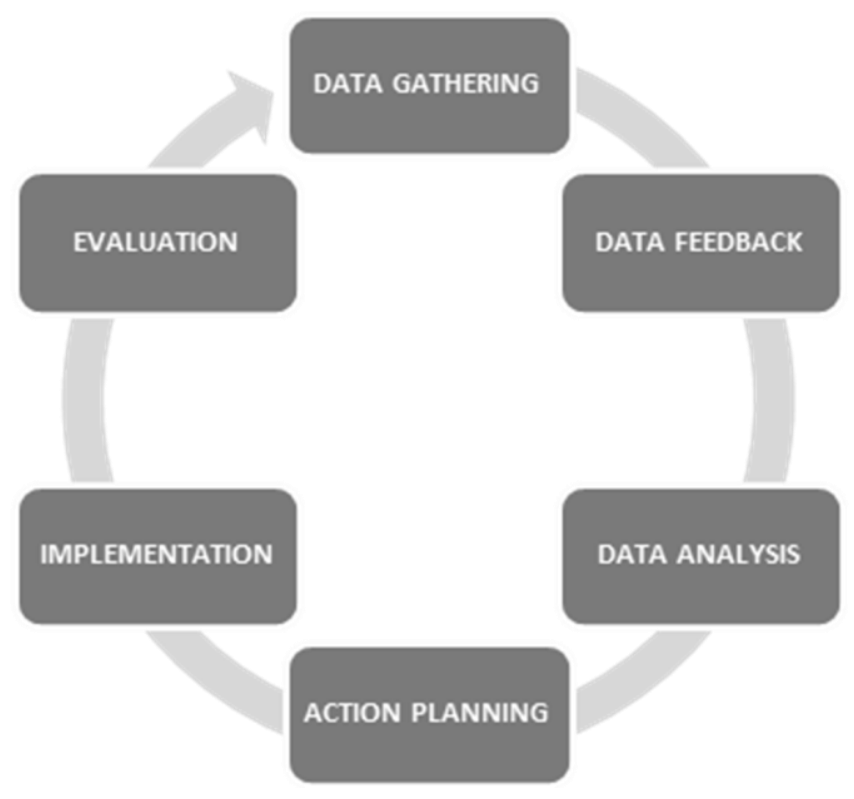

Source: Adapted from Coughlan and Coughlan (2002) 
Figure 2. Methodology

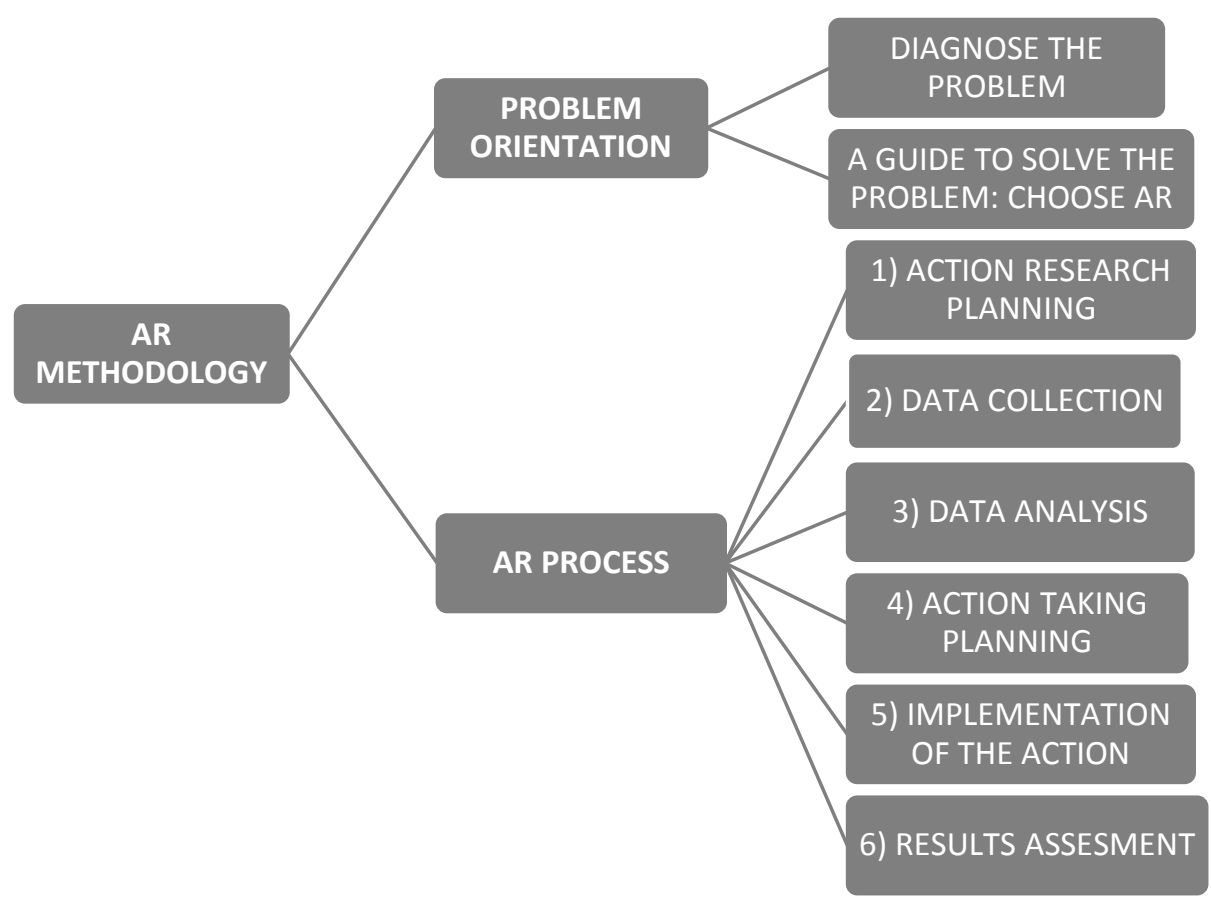


Figure 3. Number of steps taken by the waiters

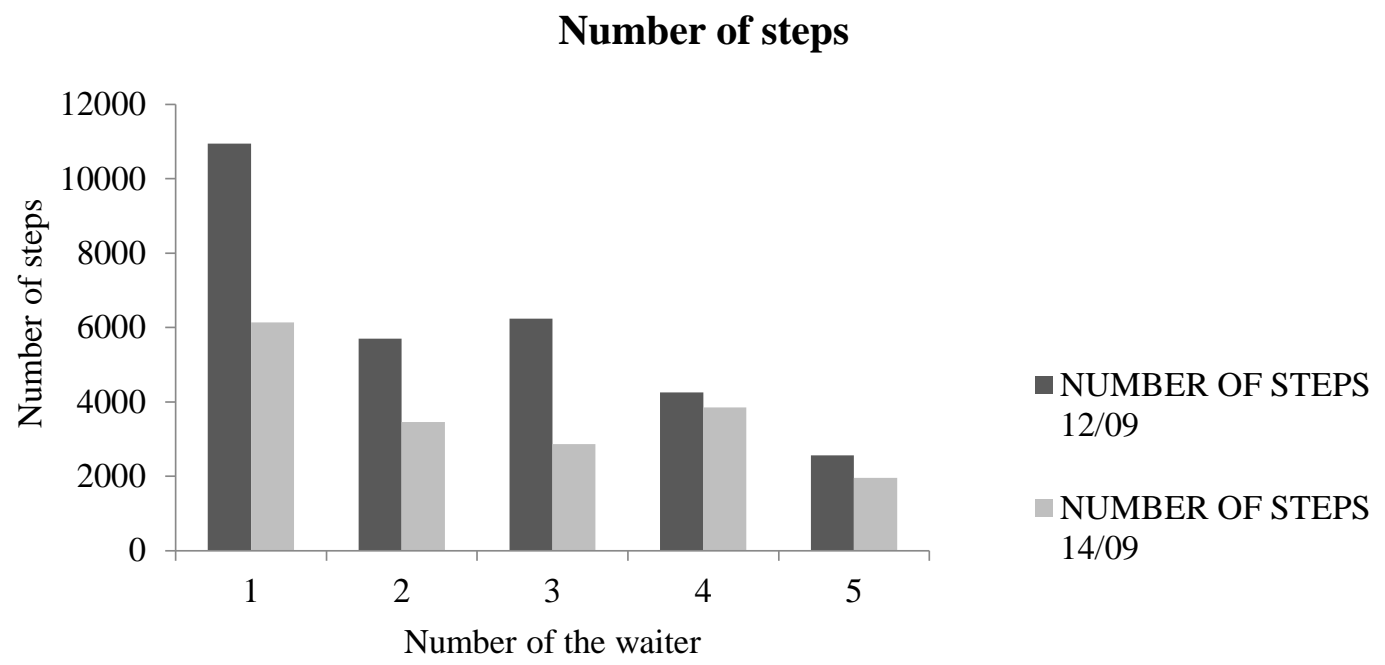


Figure 4. Linking performance management with strategies and results (Mathis and Jackson, 2007)

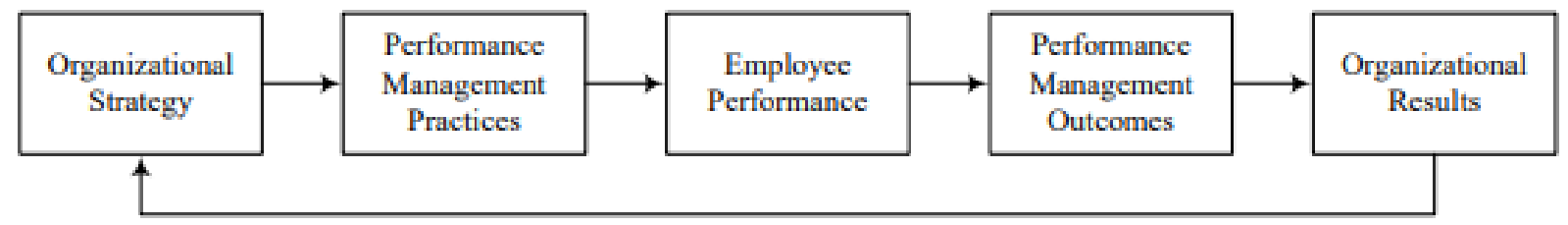


Proof-Reading-Service.com Ltd, Devonshire

To whom it may concern,

\section{RE: Proof-Reading-Service.com Editorial Certification}

This is to confirm that the document described below has been submitted to ProofReading-Service.com for editing and proofreading.

We certify that the editor has corrected the document, ensured consistency of the spelling, grammar and punctuation, and checked the format of the sub-headings, bibliographical references, tables, figures etc. The editor has further checked that the document is formatted according to the style guide supplied by the author. If no style guide was supplied, the editor has corrected the references in accordance with the style that appeared to be prevalent in the document and imposed internal consistency, at least, on the format.

It is up to the author to accept, reject or respond to any changes, corrections, suggestions and recommendations made by the editor. This often involves the need to add or complete bibliographical references and respond to any comments made by the editor, in particular regarding clarification of the text or the need for further information or explanation.

We are one of the largest proofreading and editing services worldwide for research documents, covering all academic areas including Engineering, Medicine, Physical and Biological Sciences, Social Sciences, Economics, Law, Management and the Humanities. All our editors are native English speakers and educated at least to Master's degree level (many hold a $\mathrm{PhD}$ ) with extensive university and scientific editorial experience.

Document title: Operational and Strategic Decisions in Hospitality. Lessons from an Action Research Process

\section{Author(s): Amaya Erro-Garcés and Laura Ramírez-Ávila}

Format: $\quad$ British English

Style Guide: Systemic Practice and Action Research at https://link.springer.com/journal/11213 
Table 1. Steps taken by the waiters (I)

Waiter number Number of steps Waiter number Number of steps

\begin{tabular}{lccc}
1 & 10,956 & 1 & 6,140 \\
2 & 5,695 & 2 & 3,459 \\
3 & 6,235 & 3 & 2,860 \\
4 & 4,255 & 4 & 3,854 \\
5 & 2,564 & 5 & 1,961 \\
\hline
\end{tabular}


Table 2. Steps taken by the waiters (II)

\begin{tabular}{cccc}
\hline \multicolumn{2}{c}{$\mathbf{1 4 / 0 6 / 2 0 1 9}$} & \multicolumn{2}{c}{$\mathbf{2 5 / 0 6 / 2 0 1 9}$} \\
\hline \multirow{2}{*}{ Waiter number } & Number of steps & Waiter number & Number of steps \\
1 & & & \\
2 & 9,728 & 1 & 4,822 \\
3 & 6,294 & 2 & 3,248 \\
4 & 4,837 & 3 & 2,233 \\
\hline
\end{tabular}


Table 3. Proposals to improve the catering company productivity

\section{Proposal 1 - Clarity tasks assignments}

- Workers' productivity improvement

\section{Proposal 2 - Improve the organization management}

- Reduce time of work

\section{Proposal 3 - Improve the estimation of provisions}

- Profitability improvement

\section{Proposal 4-Optimizing routes}

- Less time for the same tasks

\section{Proposal 5 - Reduce personal service}

- Less waiters for the same tasks

Proposal 6 - Modify human resources policy

- Workers' productivity improvement 


\title{
Operational and Strategic Decisions in Hospitality. Lessons from an Action Research Process
}

\author{
Amaya Erro-Garcés \\ https://orcid.org/0000-0002-1858-1363 \\ Universidad Pública de Navarra, Campus Arrosadia s/n, 31006, Pamplona, Navarra, Spain

\section{Laura Ramírez-Ávila} \\ Universidad Pública de Navarra, Campus Arrosadia s/n, 31006, Pamplona, Navarra, Spain
}

\begin{abstract}
The aim of this article is to find measures that reduce personnel costs in a catering company through the optimization of routes and tasks for staff to increase the efficiency of the company, and to transfer these measures to the sector as a whole. This paper is based on action research methodology which facilitates both taking action and creating knowledge or theory about the action analysed. Findings demonstrate that the solution focused on minimization of the workers' operations and optimization of routes does not solve the problems identified in the company. The flexibility of action research allows adaptation of the focus on the needs of the company, and both the problem and solution are redefined. Thus, a discovered relationship between operational and organizational management is the main outcome obtained in the research. As a result, six proposals are described: clarifying task assignments, improving organizational management and the estimation of provisions, optimizing routes, reducing personal services, and improving human resources policy. It is concluded that the performance of both manager and employees is influenced by the organizational strategy.
\end{abstract}

Keywords: action research; productivity; optimization; catering company; operations

Corresponding author: Amaya Erro-Garcés, Public University of Navarre, Campus Arrosadía s/n, 31006 Pamplona, Navarra (Spain); amaya.erro@unavarra.es; Tel. 0034948196081 


\section{Introduction}

According to Eurostat, the service sector is the most dominant sector in the economy. It is defined as the "current and future motor for growth in Europe" (Eurostat 2019). In this context, the tertiary sector represents almost 75 per cent of Spanish production and is responsible for two thirds of all jobs in the country.

The service sector groups many subsectors with different activities. One of them, which is the focus of this article, is the hotel sector and, more concretely, the catering sector. As stated by the Spanish Association of Franchisors (2018), the hotel sector has a great impact on the country's economy. In 2017, it contributed to 8 per cent of the national GDP. With regard to employment, the hotel sector generates around 1.6 million job vacancies each year (Aragonés, 2017). Therefore, it can be seen as one of the most important Spanish activities. On the other hand, it should be considered as a complex sector and, consequently, its organization and management are not simple.

Most of the problems handled by this sector are related to human resources management. The main difficulty is dealing with growing demand. As Garrido (2017) stated, "according to the EPA data (Active Population Survey), the service sector contributes to $75.6 \%$ of Spanish employment while before the crisis it was 9 points fewer". The increasing importance of the hotel sector and its growing demand lead to two main impressions. Firstly, employment is growing too; and secondly, it implies high expenditure. Therefore, even a company with high income assumes high personnel expenses that can lead to poor profitability.

This situation justifies the present article, which is based on experimental research in a company in the hospitality sector, Serunion, and particularly, Singularis, its catering service brand. An action research methodology is used to analyse the company and look for solutions that could be applied not just in this company, but in the sector as a whole.

In order to reduce personnel costs, the research objectives are to optimize routes and tasks for staff to increase the efficiency of the company, and to transfer the proposed measures to the sector as a whole. The main intention of this article is to find a way to reduce workers' work-time and therefore reduce costs and increase profitability. For this purpose, the research is based on observation of waiters' operation and its optimization.

The article has the following structure. Firstly, the theoretical background is presented, and then the methodology used for the research is described. Next, the process of the research is developed, starting with the planning and finishing with the analysis of the results. Finally, the article offers a series of conclusions and recommendations.

\section{Theory}

\section{Optimization of routes}


The optimization of routes and tasks solves problems in the cheapest and most efficient way. This technique has the potential to generate savings on logistical costs by defining more intelligent routes where workers spend less time at work, and the company therefore reduces its costs, in particular, personnel expenditure. At the same time, greater task efficiency supposes fewer workers involved in the same tasks, which can reduce costs further. On the other hand, as Olate (2016) affirms, new routes could imply greater satisfaction for clients derived from a better delivery rate. As a result, the company's income also increases as it attracts new customers or increases the loyalty of existing clients. However, given that there are many factors to take into account, designing optimized routes and tasks is not easy.

Several authors have studied operational optimization in the service sector. Akkerman et al. (2010) worked on the food distribution sector and the problems of quality and sustainability. Geoffrion (1974) described a model to determine the location of intermediate facilities between plants and customers for a food firm. Gelders et al. (1987) performed an analysis in the beer industry, while Wu et al. (2017) developed a distribution system for high-speed railways.

More specifically, in the catering sector, Wright and Pollert (2005) identified both positive experiences and problems encountered by ethnic minority and immigrant workers in catering routes. In a similar vein, Jansen et al. (2001) developed a simulation model in the catering supply chain.

Nevertheless, no previous research have been found to analyse catering industry operations though an action research methodology. Therefore, this study aims to fill this gap by conducting an action research study in a catering company.

\section{Action research}

Action research (hereafter, AR) is an approach to research that aims both to take action and to create knowledge or theory about the action (Coghlan 2002; Coughlan and Coghlan 2002). The term was first used by Lewin in 1946. According to Rapoport (1970, 499), "action research aims to contribute to the practical concerns of people in an immediate problematic situation and to the goals of social science by joint collaboration within a mutually acceptable ethical framework".

AR facilitates joint investigation and consulting activities and brings together researchers and companies in the case of business research. In other words, AR tries to understand the problems (research) and solve them through practice (action) — that is, it has a practical nature. Both the research and the action are part of the process (Alfaro and Avella 2013). The participation of the organization in the study will increase both the authenticity and the trustworthiness of the results, considering that the analysis is conducted in a collaborative manner (Argyris and Schön 1991). Thus, the researchers obtain more rigorous information and the study is more valuable for the entity that contracts it. However, Baskerville and Wood-Harper (1996) and Gummesson (2000) warn that consultants typically operate under tighter time and budget constraints, which may limit the ability to reflect on both the research process and the results.

On the other hand, Coughlan and Brannick (2001) contend that sometimes there are better techniques than AR to solve this type of problem. In fact, AR is adequate when the research question relates to describing an unfolding series of actions over time in a given organization, and the problem is therefore understood and a possible solution can be found (Coughlan and Coghlan 2002). The company's co- 
operation is needed in order to get all possible information and data about the problem and so arrive at a better understanding.

\section{Action research and hospitality}

Although extant publications on AR have focused on operations (e.g. Coughlan and Coghlan 2002; Karlsson and Åhlström 1996;Westbrook 1995) or education (e.g. Clift et al. 1990; Cochran-Smith et al. 1988; Gore and Zeichner 1991; Ross and Anand, 1987), this methodology has been used in the hospitality sector.

Regarding the implementation of AR in the hospitality sector, many articles focus on the hotel sector. For example, Waser and Johns (2003) worked on cross-cultural communications in hotels, Chan et al. (2013) evaluated the application of solar energy for hot water provision, and Chan et al. (2015) developed an experiment to improve air quality in hotels.

Nevertheless, the application of AR in the food industry is not new. Kocher et al. (2011) analysed the capability to innovate in a company that operated in the food industry, while Wouters (2009) developed an AR project to study a restaurant chain.

Finally, as mentioned, no previous research using the AR methodology has been found in the catering sector. This article aims to fill this gap by conducting an analysis of operational management. Once the problem has been deeply studied, the focus of the research will move from operations to strategic theory, as will be described.

\section{Action research phases}

Action research is developed in several phases, in a similar structure to other case research (e.g. Dubé and Paré 2003; Marshall and Rossman 2006; Miles et al. 1994; Stuart et al. 2002; Voss et al. 2002; Yin 2003).

As Butler et al. (2008) assert, the approach takes place in two stages. The first stage involves diagnosing the problem to be solved, the second collaborative application of the theory to guide actions to address the identified problems. However, Coughlan and Coghlan (2002) and Westbrook (1995) summarized an AR performance model that is explained in five stages: recognition and diagnosis of the problem, action planning, action taking, assessment of results, and report generation.

Figure 1 presents the phases of the methodology that should be repeated until the problem is solved. In most cases, the first cycle is not enough to solve the problem.

\section{INSERT FIGURE 1 HERE}

The AR methodology is not a fixed process; in fact, each action research has its own diverse process, as presented in Figure 2.

INSERT FIGURE 2 HERE 
It is important to highlight that $\mathrm{AR}$ is a theoretical-practical research that requires security and experience that it is not always accurate, so that the results are sometimes not as expected.

\section{Materials and methods}

\section{Data}

Firstly, it is important to contextualize the research. As mentioned, the research focuses on a catering company called Singularis. This is one of the 13,780 catering companies that constitute the Spanish catering industry, an industry that is growing continuously.

Despite the deceleration in growth, demand for catering companies is increasing. As a consequence, the problems of facing such growing demand will not disappear. Those problems have made Singularis inefficient, and lead to a larger problem: the public call for tenders for Baluarte's catering. That call was resolved last August in favour of another company, Vicastelar Services S.L. This company will start its business in Baluarte in 2019. This decision implies that Singularis will not work in Baluarte's catering services.

\section{Diagnosis and problem definition}

Serunion, the business group to which Singularis belongs, is a company created 30 years ago. It offers catering services in different places around the country. In this case, the study is focused on the catering offered in Baluarte, a building for cultural events in Pamplona, Navarra.

Among the objectives of the company, the wish to serve quality dishes meeting nutritional requirements to offer a quality and healthy diet can be highlighted. As the official website shows, the company has around 2,920 food centres. Therefore, it can be expected that the pre-service work is complex to manage and the company spends a long time organizing different diets, dishes and menus depending on the place, time and clients. Serunion has around 470,000 diners daily around all the national centres, with an annual turnover of 445 million euros or more.

However, the company has a problem deriving from the huge cost of hiring staff. Serunion has more than 19,000 employees with which to face the growing demand. Because of the growing costs, there is a wish to optimize the cost of personal in the catering services in Baluarte. This optimization aims for a service with the greatest viability and quality, at all times meeting the clients' requirements.

To perform the optimization, and according to the information facilitated by the company, workers are paid according to the hours worked. Therefore, the fewer hours worked, the lower the salary and the higher the saving for the company. It is important to keep in mind workers' profiles. This is a case study where the workers are occasional: they are hired exclusively to offer services for different events during specific hours. The structure of the workforce is sixty per cent student and thirty per cent people that were unemployed; the rest are people working in the sector. Accordingly, this type of worker is not the most effective, particularly in the Baluarte building, which is very complex and it is easy to get lost: in fact, if workers were permanent, there would be fewer problems. 
Because of the complexity of the building and the profile of the workers, the waiters take too much time preparing the rooms in which the events are held. Moreover, the preparation and service of the dishes also take a long time. The solution to these problems is the optimization of routes, together with some different techniques to optimize the time spent on different tasks.

Through this mechanism, there will be new and more efficient assignments that save workers' time. These problems were described by the company, and managers from the company took an active role in defining the main research questions jointly with the researchers. It is important to emphasize that an interactive relationship between the researchers and the workers - in this case, waiters - is essential in AR. If they do not collaborate, it is be almost impossible to develop an AR project.

\section{Action research planning}

The first decision is related to the value of developing the research. The expected improvement for the company if the problem is solved should be considered. In this sense, the personnel costs for the company are analysed, as they are the highest expenditure. Seeking a reduction in these costs will suppose a significant improvement for the company and, as a result, the research is of value. The company's decision about the research was relevant to decide the focus of the study. Managers showed the importance of the research to understand the main variables that determine the company's productivity. As a result, the research was approved and the company decided to participate actively in the process.

Another factor to include in the analysis is related to the cost of the research. In this case, the research incurs no costs. If there were costs, the company should evaluate the profitability of developing the research or not and compare the results.

After deciding to carry out the research, the researchers should ask themselves how the problem might be solved. The problem of the catering company case could be answered, in principle, by optimizing the operation of the waiters. As mentioned, the problem was jointly described with the organization. Managers pointed about importance of the costs and optimization of the operational process. Nevertheless, according to AR methodology, this plan is not unchangeable; in fact, it will vary as the research goes on.

In this step, it is important to make sure that the chosen methodology is the right one. The previous section tested this with a deep explanation of AR, concluding that the action research process is the best way to resolve the issue.

Finally, a critical analysis of the expected results is required. In the studied case, an improvement in workers' productivity is expected, reducing personnel costs and increasing the company's benefits. This should be calculated numerically and the company should participate in its analysis.

\section{Data collection}

Data were collected mainly through an observation technique, although some information was given by the event organizer. 
- Place where the action research will be carried out: Baluarte (Pamplona, Navarra)—specifically, the rooms or spaces where the catering services are developed.

- Members who are going to be studied: Waiters in charge of serving at the different events. This information is not always the same. The workers are hired casually; therefore for each of the events around which the research is based, the workers were different. It might be more accurate if the research involved the same workers.

- Participatory research: The organization was involved in the research process in several ways. Managers from the company helped the researchers to define the events that represent the whole activity of the company. Data justifying the selection of the event were shown by the company.

- Data collection

i. Data collection method: Data collection was through an app on workers' mobile phones which counts the steps of each worker. The name of the app is Podómetro. The Podómetro app is a free download that records the number of steps taken and shows the caloric consumption distance, walking time and speed. It measures the effort of each of the workers and the distance of their routes. Each waiter downloaded it on their mobile. They pressed the start button just before starting to work, and at the end of the work time they recorded the number of steps taken. The app therefore started working when the workers began preparing the room and it stopped working when they finished clearing everything. The organizer had to ask permission for the waiters to carry the mobile with them; they are not otherwise allowed to use mobiles during an event.

ii. Date of the collection: From March to July, the planning of four different events was analysed. Data were collected from the events from September to November.

iii. Data analysis: The analysis is finally described in the next section.

\section{Data analysis}

To collect data, the operation process in different events is observed , as the company offers a wide range of different catering services but there is a process that every event follows.

The first issue considered is the event size, depending on which the company decides on the number of workers to hire. The staff used include cooks, waiters, a head waiter and an organizer. In contrast to the waiters, the roles of head waiter and organizer are always given to the same person.

The working day of the staff begins before the event. The cooks work hard from very early in order to get the food ready for an event; the waiters also start working some hours before since, apart from serving the food, they also have to prepare the event room and a space, called the office, next to the event room. This research is focused on the waiters' work.

As mentioned, the workers are in charge of preparing the event space. This action takes between an hour and an hour and a half, depending on the event size. However, because of the complexity of the building, the time to prepare will also vary depending on the floor where the event is located. The main issue is that the things needed to prepare the room are on different floors of the building. For example, the kitchen is 
in the basement -1 , while the tables and the tableware are on the second and third floors respectively. Moreover, the routes involve the use of just two lifts. Therefore, the routes to prepare and collect are complex and difficult to optimize.

On the other hand, the waiters also have to prepare an office next to the event room. The aim of this small space is to have everything at hand to serve. It is next to the main room to allow the simplest and shortest route to serve the food. Therefore, optimization of routes and actions is focused on the preparation and the clearing.

Preparation of the event room consists of assembling the necessary tables and dressing them. There is also a bar, used for the purchase of special drinks. The office room is where the cooks plate the dishes and where the waiters collect and return their trays.

The distribution of the waiters around the room is decided by the head waiter. Just a few minutes before starting the event, there is a meeting in which the head waiter assigns each worker their task during the event. Basically, the distribution consists of putting someone in charge of drinks and others in charge of the food. Moreover, there is always one waiter, at least, in charge of the bar.

After the event, the waiters have to clear the room and the office. They have to collect all the glasses, plates and cutlery in order to wash them. They also have to collect the tableware for washing, and collect and store the drinks and glasses not used during the event.

Although the research is based on more events, two particular events will be considered to demonstrate the problem in the company.

12th September. Cocktails were served for guests at a Law School lecture. The even took place on the ground floor and the number of guests was around 300. In this case, the company decide to hire 11 waiters and waitresses to manage 12 tables. The average number of guests per worker was approximately 30. In addition to these workers, the head waiter and the organizer were at the event.

The event started at 13:15 and all the waiters worked from 11.30. In this event, they had to collect the furniture to assemble in the hall from floor-1 and the second floor. The event lasted until 15.00, at which time the waiters had to clear everything. A few minutes before 13:15, the worker head told them that one of the waiters was going to be located in the bar, half of them were in charge of drinks, and the other half were in charge of the food.

Although the workers' route to serve the food was quite simple, complex routes were used to prepare the rooms. To prepare this event required equipment from the basement -1 , where the kitchen is located, and from the second floor warehouse.

14th September. This event was smaller; the guests numbered around 150 people. The cocktails were prepared for a lecture about the integration of occupational health and public health. The company hired five waiters, so the average was 25 customers per worker. Their working day started at 12:30 and the 
cocktail party started at 13:45. The cocktail party took place on the third floor, which made preparation easier: the tables were on the same floor, and they also just needed some tableware from the basement -1 .

There were six tables and a bar, so, there were four waiters around the room and a waiter behind the bar. The waiters serving the cocktails were distributed according to their tasks: three were in charge of serving the food and one was in charge of collecting the rubbish and the empty glasses from the tables.

The event lasted until 14:40, but the waiters did not clear the room. The next day, 15th September, there was a wedding in the same room, so they took advantage of this and, instead of clearing it, they put in more tables and chairs to prepare the room for the wedding.

This event was simpler than the previous one. The workers took the equipment from the same floor as the event, so the only route was from the kitchen to the event floor.

Every event needed to carry the food from the kitchen to the event floor. Depending on the floor on which the event was being held, the route varied, but there was always a need to use the lift to move between floors.

On the other hand, the tableware was stored on the second and third floors.

The Podómetro app also counted the steps taken by the waiters. Table 1 shows the number of steps taken.

\section{INSERT TABLE 1 HERE}

The table differentiates the events in order to compare the productivity of both events. Figure 3 contributes to the analysis and comparison of the events.

\section{INSERT FIGURE 3 HERE}

Observing the data, several conclusions can be drawn. The data show some differences among workers. These differences can be interpreted in different ways, one of which is related to productivity.

From the data collected from the app, it can be observed that there is a waiter who takes fewer steps, specifically waiter number 5. It is assumed that this worker is the one working in the bar (Table 1). That worker is not busy most of the time, so will take fewer steps than the others.

Nevertheless, there are still differences among the rest of waiters. These variations are considered as the differences in productivity and differences in the length of the routes taken. There are two ways to interpret them. On one hand, it is expected that the workers who take more steps are more productive, since they work more; but, on the other hand, it is also possible that the workers who take more steps are less efficient.

Regarding the latter thought, in general terms, when the worker has only recently been hired, he is likely to get lost in the building: it takes a while to learn the routes and to get used to the pace of work. In addition, workers will sometimes, in order to work less and put in less effort, pretend that they got lost. 
However, there are also reasons in favour of the notion that waiters taking more steps are more therefore complete a task more quickly, thus taking on more tasks than another waiter and, as a consequence, taking more steps. This fits the role of the more experienced waiters.

During observation of the events, it was concluded that this case supports the idea that the workers who take more steps are the most productive workers. That does not mean that this will be true in all caseseach case has its own interpretation-but it is the case here. Here, the worker who took most steps (waiter number 1 , Table1 is also the most experienced worker.

Another important point to take into account to analyse the data from the app is that waiters knew that someone was watching and evaluating them. As a consequence, some of them were probably working more productively than if nobody was watching. This can be generalized to any worker, as every worker tries harder when they know they are being watched. It is also true that this method does not automatically improve productivity, since it can sometimes encourage workers to pretend that they are working.

There are further differences between the two events. Because the events took place on different floors, it was not possible for the workers to take the same number steps in the different spaces. For example, events which are held on the ground floor, as it is a bigger space, will cause workers to take more steps than events on the third floor. The distance between the office and the event room also affects this situation.

\section{Action planning}

After analysing the data, some conclusions can be arrived at. Firstly, a better definition of the problem can be achieved. The problem being faced is lack of productivity as a whole. It is true that there are problems with workers' productivity, but also there is the need to improve organizational strategies.

Because of the complex distribution around the building of the equipment necessary to prepare the event room, waiters spend a lot of time moving things upstairs and downstairs when preparing and clearing up. As the distribution of the things cannot change, this research seeks to find the best routes to minimize the working time.

Taking into account all the information observed, action planning is based on six proposals.

\section{Proposal 1. Clarify task assignments}

The first proposal to minimize working time is to improve the planning of tasks. The research shows that the working day starts with all the waiters setting out the event room and the office. When the event is large, the company hires many waiters and there are therefore too more waiters than are needed to set out the room. Taking into account that there are only two lifts, the routes will be more efficient with fewer waiters setting out the spaces. The recommendation is to reduce the number of waiters setting out the room. 
Moreover, the distribution of tasks must be clarified - that is, each worker should know what his aim is at every moment. The objective is to reduce the working time of every worker, so if they distribute more simple tasks, the productivity of the waiters will improve.

Indeed, the idea of each waiter knowing his or her task just a few minutes before the event may not be the best. It would be helpful for the waiters to know their tasks as soon as they start working. Even more, they should not change their assigned tasks for different events: that would be helpful for a waiter repeating the task at the next event, and would lead to specialization.

\section{Proposal 2. Improve organization}

This proposal is related to the distribution of the office. As was explained, the office is the place where everything is prepared to serve the food.

The organization of the office is not the best. There are usually tables where the cooks have to plate the food, and the waiters have to serve the beer, prepare their trays, and leave the rubbish, plates and glasses collected from the event room. All these actions are done using the same tables without any organization. The only differentiation is between the cooks' and the waiters' place. If there is better organization of the tables, workers will be faster and they will spend less time.

\section{Proposal 3. Improve estimations}

The next proposal focuses on the differences between estimation and the real situation. The waiters have traditionally prepared drinks and food for the events - that is, estimated the drinks, food and services that will be used for an event. However, that estimation usually does not fit with the real situation.

It is evident that it is better to have too much than too little; but the problem is that everything prepared to serve that is not served must be collected again, and it requires more time spent working. If the estimations are more adjusted to the reality, the waiters will save working time.

Moreover, better estimation will increase the benefits for the company. If waiters prepare just the quantity to serve, there will be less waste and there will be better use of the food and drinks by the company.

\section{Proposal 4. Optimize the routes}

The optimization of routes is one of the principal objectives of the research, so a plan is needed to implement better routes. The routes can be optimized in several ways. One of them is mentioned in the proposal 1: the waiters should be assigned different tasks to help create more efficient routes to set up the spaces.

On the other hand, routes could be made more efficient by using a trolley to move things in a faster and more comfortable way. The waiters dress the tables bringing equipment on trays: they would take less time using a trolley, since they can bring more things in a single trip and with less risk of dropping it.

Proposal 5. Reduce personal service 
The food is served by the waiters. They take their trays with drinks and food from the office and they go This proposal seeks to leave some foods and drinks on the tables. In the case of drinks, they already do, except with the beer. But, in the case of food, the company will need fewer waiters if they leave some of the snacks on the table.

Hiring fewer waiters means a reduction in personnel costs, and this leads to an increase in the company's benefits. This completes another of the company's objectives.

\section{Proposal 6. Modify the human resources policy}

The human resource policy followed by Serunion is based on casual work contracts. As mentioned at the beginning of the article, a high proportion of the waiters are students with no experience, and the rest of the worker are foreigners who are working on this job because they cannot find another one.

The proposal is to change the way to hire waiters. The company should look for loyal and experienced waiters. This would increase the productivity of the company in many ways. For example, the workers will not need a lot of preparation time. Another point is that if the workers work for the company for a long time, the complexity of the building will not be a problem.

Once we have the proposals for action, the next step is to implement them.

\section{Implementation of the actions}

This step of the research differs a little from the general process. This is because Serunion lost its place in Baluarte last August through a call for tenders, and so the company will not be able to implement the actions. In the place of Serunion is a new company, Vicastelar Servicios S.L.

At NICDO (Navarra Infraestructuras de Cultura, Deporte y Ocio), the process to choose the new company was based on economics, sustainability, brand and image, and logistics and services.

Taking into account these components, Vicastelar Servicios S.L. made the best offer. They were valued because of their use of seasonal and local raw materials and because of the development of a corporate social responsibility programme. Moreover, they stated that "The Company makes a social commitment that favours labour insertion - including people with disabilities or functional diversity — and promotes equal opportunities, and also guarantees the subrogation of the staff currently employed." This supports the proposal of changing the human resources policy.

According to its business in Baluarte, Vicastelar Servicios S.L. is in charge of the coffeeshop, and three restaurants inside the building, one on each floor. The restaurant located in the ground floor is a finger food restaurant - that is, a restaurant serving food that can conveniently be eaten with the fingers. However, the restaurants on the second and third floors offer a gourmet menu specializing in vegetables. 
Apart from these services, the company also offers the catering service on which we have focused the research. Concretely, the services will be for events, weddings and banquets. The company also organizes the coffee shop service and fixed and mobile bars.

Despite the fact that Serunion will not implement the actions recommended in Baluarte, the research could help both Serunion and the mentioned new company. Regarding Serunion, implementation of these proposals could improve many of the other businesses of the company. The research can be useful in relation to similar problems in other places, because the way the company operates in Baluarte is perhaps similar to the way it operates elsewhere, and it might have problems with organization of which it is not aware.

New data collection was performed in June 2019, after modifying the human resources policy (new waiters had previous experience and they had higher training), clarifying the previous tasks of each employee, decreasing the quantity of drinks and food, and reducing the number of waiters. Two cocktail parties pertaining to a meeting in Plant Science and GICCA 2019, an Ibero-American Conference, were selected to measure the operational process. Table 2 shows the outcomes of the new measurements.

\section{INSERT TABLE 2 HERE}

Just four waiters worked at each event. All employees reduced their step count for the first event, except for waiter number 2 .

If we compare total steps from the first measurement and the second, in 2018, 47,979 steps were counted, whereas in 201938,705 were taken to perform the same service, which is a reduction of 19.32 per cent.

More experienced and trained employees imply higher wages. However, as the new catering company has reduced the number of employees, total expenditure has been reduced. As a result, workers' productivity has improved.

Despite the research being focused on a specific company and a specific situation, its conclusions are also appropiate to most service sector companies. The organization management of the business is as important as the operations management. That is, the operation of a company depends on the workers' productivity, but it also depends on the department that coordinates and organizes their tasks. Therefore, most of the proposals can be generalized to different companies.

For example, the first proposal is applicable to any company. Every worker will work in a more efficient way when the tasks assigned are clear. Here, neither the building nor the company matters: the productivity of a worker will increase when the tasks are clear, independent of the context.

The same reasoning can be applied to the sixth proposal. The human resources policy significantly affects workers' productivity. When a worker is loyal and permanent in a company, he or she would be more satisfied and, as a consequence, the worker will be more productive. 
Other proposals can be applied to some companies of the sector, like the third proposal. The estimation of materials is essential for any company in any catering sector. If these materials do not fit the needs, there can be huge losses for the company.

It can therefore be concluded that the proposals made can be implemented in many other companies in addition to Serunion and Vicastelar Services S.L. The implementation leads to a new analysis, which is of the consequences or results.

\section{Results and discussion}

This section analyses the consequences of the implementation of the actions. Table 3 shows the consequences expected of each of the proposals identified to improve and solve the problem.

\section{INSERT TABLE 3 HERE}

The proposal of assigning the waiters to clearer and simpler tasks leads to faster work, since they are focused on their tasks instead of looking for something to do. Furthermore, if they repeat the same task over time, they will reduce the time needed to perform the task.

The second change gives rise to a more organized way to work, in that the waiters spend less time in the office searching for a place to put dirty cups and plates on the table. At the end of the event, they also spend less time clearing the office.

Regarding the third proposal, the waiters spend less time both preparing and clearing overestimated food, drinks and glasses. It also saves the company money, since it uses almost all the estimated quantities without creating a surplus.

The fourth and fifth proposals refer to the main objective of the research - that is, to optimize the routes of the waiters. This saves money through the need to hire fewer workers while, at the same time, they complete the same tasks faster and more effectively.

Finally, the change of human resources policy implies a huge improvement for the company.

Apart from the expected results, it is important to highlight some further implications of the research. Regardless of the implementation of the action, the research shows the strong relationship between operations and organization management. This suggests that proper allocation of the organization's resources, such as the workers, is essential to achieve the objectives of the company.

Brown et al. (2013) argue that most CEOs and other senior-level managers struggle to articulate a strategy, but they fail to share and implement the strategy with all employees. This is made worse because many CEOs know very little about operations management.

In this vein, Mathis and Jackson (2007) show the importance of having the right human resource management for the company's strategies. Figure 4 presents the relationship between the organizational strategy and its results. 


\section{INSERT FIGURE 4 HERE}

As Figure 4 shows, the performance of the management of both practices and employees is influenced by the organizational strategy. At the same time, the outcomes of the company depend on that performance.

As a conclusion, the solution to the performance of workers is related to revision and improvement of the organizational strategy. Once the optimal organizational strategy is found, the results of the company will improve in terms of both productivity and profitability.

\section{Conclusions}

Action research is proposed as the best way to find the solution to the problems identified in a catering company that aims to reduce personnel costs. As AR is individualized and flexible, it allowed researchers to recognize more problems than the ones initially identified. The research focused firstly on the optimization of routes. Nevertheless, more problems were found related to organization management difficulties.

As a result of the complexity of the building, the routes of the waiter cannot change; they are already taking the simplest way. However, the company can improve its productivity by adapting and altering several operational aspects. As a result, six proposals are identified: clarifying task assignment, improving organizational management and the estimation of provisions, optimizing routes, reducing personal services and improving the human resources policy. The first proposal is the need to clarify the tasks assigned in order to perform more productively. The second proposal is related to making better estimations of the provisions required for each event. Through this technique, both profitability and productivity improve. At the same time, the fourth and fifth proposals lead to the same tasks being performed in less time and by fewer workers. Optimizing the routes and reducing the personal service improve both productivity and profitability. Finally, changing the human resources policy helps to form a loyal and permanent workforce. It improves the workers' satisfaction and therefore their productivity.

The implementation of these proposals is essential for the research and, in this case, a new company conducted the implementation. They performed the same service in the same location. Furthermore, this new company has a different human resources policy which allows us to study the implementation of the sixth proposal. Indeed, the proposals can be implemented not just in the new company, Vicastelar Services S.L, but also in many other companies in the sector.

Overall, the research has highlighted a significant relationship between operations management problems and organizational strategies. As has been explained, having the right people in the right place at the right time is critical to make the overall strategies work. Therefore, if the workers' organization strategy is not synchronized with the operational strategies, problems appear. In order to avoid problems, the optimal solution is to work on the organizational strategies. 
Like every research, this study presents some limitations. Firstly, there were difficulties measuring the implementation of the proposals defined, as a new company is in charge of the hospitality service. Secondly, the conclusions depend on the situation of the catering company analysed. Nevertheless, human resources problems are found in most companies in the sector. For that reason, the conclusions are also relevant for other companies.

Further research should include measurement of the identified proposals in other companies in the sector. Developing new analyses in different countries and cultures will facilitate extending the results to other contexts.

\section{Funding}

This work was supported by the Ministerio de Economía, Industria y Competitividad and Fondo Europeo de Desarrollo Regional (FEDER) under Grant ECO2017-86305-C4-4-R. 


\section{References}

Akkerman R, Farahani P, Grunow M (2010) Quality, safety and sustainability in food distribution: a review of quantitative operations management approaches and challenges. OR Spectrum 32(4):863-904. https://doi.org/10.1007/s00291-010-0223-2

Alfaro JM, Avella L (2013) Investigación en acción: cómo impulsar la contribución de la universidad en la competitividad de las organizaciones. Harvard Deusto Business Research 2(2):89-101. https://doi.org/10.3926/hdbr.33

Aragonés J (2017) La hostelería supone un 8\% del PIB nacional. Efe Empresas. Madrid. 11 August 2017. https://www.efeempresas.com/noticia/hosteleria-8-pib-nacional/ Accessed on January 2019.

Argyris C, Schön D (1991) Participatory action research and action science compared. In: Whyte WF (ed) Participatory action research. Sage Focus Editions, London. http://dx.doi.org/10.4135/9781412985383

Baskerville R, Wood-Harper T (1996) A critical perspective on action research as a method for information systems research. Journal of Information Technology 11(3):235-246. https://doi.org/10.1080/026839696345289

Brown S, Bessant J, Lamming R (2013) Strategic operations management. Routledge, London.

Butler T, Feller J, Pope A, Emerson B, Murphy C (2008) Designing a core IT artefact for knowledge management systems using participatory action research in a government and a non-government organisation. The Journal of Strategic Information Systems 17(4):249-267. http://dx.doi.org/10.1016/j.jsis.2007.10.002

Chan W, Lee SC, Hon A, Liu L, Li D, Zhu N (2015) Management learning from air purifier tests in hotels: experiment and action research. International Journal of Hospitality Management 44:70-76. https://doi.org/10.1016/j.ijhm.2014.10.007

Chan WW, Li D, Mak B, Liu L (2013) Evaluating the application of solar energy for hot water provision: an action research of independent hotel. International Journal of Hospitality Management 33:76-84. https://doi.org/10.1016/j.ijhm.2013.01.008

Clift R, Veal ML, Johnson M, Holland P (1990) Restructuring teacher education through collaborative action research. Journal of Teacher Education 41(2):52-62. https://doi.org/10.1177/002248719004100207

Cochran-Smith M, Kahn J, Paris CL (1988) When word processors come into the classroom. Writing with computers in the early grades, 43-74.

Coghlan D (2002) Interlevel dynamics in systemic action research. Systemic Practice and Action Research 15(4):273-283.

Coughlan P, Brannick T (2001) Doing action research in your own organization. Sage Publications, London. 
Coughlan P, Coghlan D (2002) Action research for operations management. International Journal of Operations \& Production Management 22(2):220-240. https://doi.org/10.1108/01443570210417515

Dubé L, Paré G (2003) Rigor in information systems positivist case research: current practices, trends, and recommendations. MIS Quarterly 597-636.

Eurostat (2019) Annual national accounts. https://ec.europa.eu/eurostat/data/database

Garrido HM (2017) España revive por los servicios, el único sector que recupera el empleo y PIB perdido en la crisis. 20 minutos. Madrid. 15 May 2017. https://www.20minutos.es/noticia/3033212/0/espanasector-servicios-base-recuperacion/ Accessed on January 2019.

Gelders LF, Pintelon LM, Van Wassenhove LN (1987) A location-allocation problem in a large Belgian brewery. European Journal of Operational Research 28(2):196-206.

Geoffrion AM (1974) Lagrangian relaxation for integer programming. In: Approaches to integer programming. Springer, Berlin, pp 82-114.

Gore JM, Zeichner KM (1991) Action research and reflective teaching in preservice teacher education: a case study from the United States. Teaching and Teacher Education 7(2):119-136.

Gummesson E (2000) Qualitative methods in management research. Sage, London.

Jansen DR, Van Weert A, Beulens AJ, Huirne RB (2001) Simulation model of multi-compartment distribution in the catering supply chain. European Journal of Operational Research 133(1):210-224.

Karlsson C, Åhlström P (1996) Assessing changes towards lean production. International Journal of Operations \& Production Management 16(2):24-41.

Kocher PY, Kaudela-Baum S, Wolf P (2011) Enhancing organisational innovation capability through systemic action research: a case of a Swiss SME in the food industry. Systemic Practice and Action Research 24(1):17-44.

Lewin K (1946) Action research and minority problems. Journal of Social Issues 2(4):34.

Marshall C, Rossman G (2006) The how of the study: building the research design. In: Designing qualitative research, 55-101.

Mathis RL, Jackson JH (2007) Human resource management. South-Western College Pub, Cincinnati.

Miles MB, Huberman AM, Huberman MA, Huberman M (1994) Qualitative data analysis: an expanded sourcebook. Sage, London.

Rapoport RN (1970) Three dilemmas in action research: with special reference to the Tavistock experience. Human Relations 23(6):499-513. 
Ross SM, Anand PG (1987) A computer-based strategy for personalizing verbal problems in teaching mathematics. ECTJ 35(3):151-162.

Spanish Association of Franchisors (2018) Franchising in Spain report 2018. http://www.franquiciadores. com/wp-content/uploads/2018/04/Franchising-in-Spain-AEF-National-Statistics-2018.pdf Accesed on January, 2019.

Stuart I, McCutcheon D, Handfield R, McLachlin R, Samson D (2002) Effective case research in operations management: a process perspective. Journal of Operations Management 20(5):419-433.

Voss CT, Tsikriktsis N, Frohlich M (2002) Case research in operations management. 22(2):195-219.

Waser H, Johns N (2003) An evaluation of action research as a vehicle for individual and organisational development in the hotel industry. International Journal of Hospitality Management 22(4):373-393.

Westbrook R (1995) Action research: a new paradigm for research in production and operations management. International Journal of Operations \& Production Management 15(12):6-20.

Wouters M (2009) A developmental approach to performance measures-Results from a longitudinal case study. European Management Journal 27(1):64-78.

Wright T, Pollert A (2005) The experience of ethnic minority workers in the hotel and catering industry: routes to support and advice on workplace problems. Working paper.

Wu X, Nie L, Xu M (2017) Designing an integrated distribution system for catering services for highspeed railways: a three-echelon location routing model with tight time windows and time deadlines. Transportation Research Part C: Emerging Technologies 74:212-244.

Yin RK (2003) Case study research: design and methods. Sage, Thousand Oaks, CA, London. 